\title{
AS EPIDEMIAS E A MORTE: mudanças nas práticas de sepultamento em São Luís na segunda metade do século XIX (1854 - 1856).
}

\author{
Agostinho Júnior Holanda Coe
}

Mestrando em História Social pela Universidade Federal do Ceará/Bolsista Capes.

Resumo: Discussão das epidemias que assolaram São Luís ao longo do século XIX e sua relação com as mudanças nas práticas de sepultamento. Os conceitos sobre os paradigmas de modernidade na capital implicavam julgamentos do que devia ou não ser preservado, do que seriam bons e maus lugares, progresso e atraso, estabelecendo normas a serem seguidas. Uma das principais medidas a serem implementadas com o intuito de fazer do ambiente urbano ludovicense um lugar mais higiênico, era acabar com os sepultamentos nas igrejas e transferi-los para locais distantes do espaço citadino. Com isso, buscava-se diminuir a incidência dos vários surtos epidêmicos que assolavam a cidade no decorrer do século XIX, dirimindo a ação dos miasmas, vapores pestilentos causadores de malefícios físicos aos vivos.

Palavras-chave: Higiene - Epidemias - Sepultamentos - Cemitérios

\begin{abstract}
Discussion about the epidemics that afflicted São Luis during the XIX century and their relation with the burial practice changes. The concepts of modernity paradigms at the capital means judgments about what should or not should be preserved, about what would be good and bad places, progress and decadence, establishing rules to be followed. One of the main actions that would be taken to wanting to turn into the ludovicense urban environment a more hygienic place, was get through with burial in the churches and move it to far way places of the city area. So, aim to decrease the great numbers outbreak of epidemics that afflicted the city during the XIX century, ceasing the actions of miasmas, plague vapor causer of physical bad to the alive.
\end{abstract}

Keywords: hygienic - epidemics - burial - cemetery.

Notadamente na segunda metade do século XIX, São Luís buscou de forma mais presente uma reorganização do seu espaço urbano. A cidade, que para a época era carente de regras mínimas de organização pública, teria que passar por profundas modificações com o intuito de proporcionar um ambiente urbano mais saudável para os seus habitantes. A partir dessas transformações, em São Luís desencadeou-se uma luta entre 
o que seria o "progresso" e a "tradição", pois para a constituição de uma cidade moderna era preciso destruir para construir, remodelar o espaço em função da técnica, da higiene, da estética, estabelecendo a norma e a transgressão, o público e o privado.

Ao analisar esse processo de "racionalização" da cidade de São Luís no século XIX, é preciso levar em consideração a existência de diversos discursos que, embora interligados, mantêm suas particularidades. Especialmente na segunda metade do século XIX, busca-se uma cidade sonhada e desejada em projetos arquitetônicos e que também pudesse ser entendida a partir de múltiplos olhares: médicos, políticos, urbanísticos, literários, policiais, jurídicos, cada um analisando a partir do seu lugar social e em busca de fazer da capital maranhense um "exemplo" de cidade moderna.

Dentre essas várias construções teóricas, havia o ideário médico que buscava uma urgente reorganização e saneamento do espaço urbano ludovicense. Diante desse contexto, havia uma grande preocupação com as epidemias que assolaram a cidade principalmente ao longo do século XIX, e que para as autoridades locais tinham relação com o descaso da população para com as mínimas regras de higiene ${ }^{1}$.

Procuraremos, portanto, discutir neste artigo a relação entre o desenvolvimento do higienismo em São Luís e as mudanças nas práticas de enterramento. Além disso, analisaremos até que ponto as epidemias que assolaram a cidade durante praticamente todo o século XIX, foram importantes na reformulação de algumas práticas relacionadas ao cotidiano da morte ludovicense.

O recorte temporal busca problematizar o início do surto de varíola em São Luís no ano de 1854 e que vai levar a reformulação de diversas práticas cemiteriais, finalizando a temporalidade estabelecida em 1856, haja vista que neste ano começa a remissão do surto variólico e amadurecimento do discurso higienista, no que diz respeito aos enterramentos na capital.

Um dos principais alvos do higienismo era justamente os sepultamentos realizados dentro das igrejas, pois ali estaria um grande foco de propagação de doenças.

\footnotetext{
${ }^{1}$ Entre o final do século XVIII e início do século XIX, a higiene tornou-se um paradigma dominante quando o assunto em questão era o processo civilizador. Desenvolveu-se a idéia de que as doenças contagiosas eram predominantemente transmitidas pelo ar sendo preciso, portanto, estabelecer o controle do estado via medicina sobre os hospitais, escolas, asilos, cadeias, cemitérios, prostíbulos. Ver: VIGARELLO, Georges. O limpo e o sujo: uma história da higiene corporal. São Paulo: Martins Fontes, 1996; CRESPO, Jorge. A História do Corpo. Lisboa, Difel, 1990.
} 
Como os templos religiosos ficavam quase sempre em lugares de destaque no panorama urbano, recebendo ainda um grande fluxo de pessoas, a ciência médica do século XIX passou a difundir a idéia do caráter pernicioso das sepulturas eclesiásticas, acreditando que os enterramentos nos templos eram foco de propagação de vapores pestilentos que ajudavam na perpetuação de surtos epidêmicos.

São Luís, praticamente durante todo o século XIX, segundo a documentação aqui analisada ${ }^{2}$, foi duramente castigada por sucessivas e freqüentes epidemias - e ao que parece cada novo surto epidêmico era sempre de maiores e lamentáveis conseqüências para a população. A propalada precariedade higiênica quase que permanente da cidade contribuía, segundo as autoridades médicas, decisivamente para a proliferação de doenças. Segundo César Marques ${ }^{3}$ (1870, p. 194), o primeiro grande surto de varíola no século XIX aconteceu em 1836. Em 1840, reapareceu a varíola que atingiu grande força em 1841, diminuindo sua intensidade em 1842. Em 1846, novamente temos a varíola acometendo a cidade, até chegarmos ao surto de 1855, que levou São Luís a sofrer as agruras das epidemias ainda de forma mais avassaladora.

De acordo com Sidney Chalhoub (1996, p. 168-169) havia dois paradigmas médicos principais no que diz respeito à propagação de doenças epidêmicas no Brasil. Um seria a idéia do contagionismo, ou seja, a capacidade que certas doenças teriam de comunicação direta entre indivíduos, por meio de objetos contaminados ou pelo ar corrompido. A varíola seria um exemplo de doença contagiosa. Outro seria o infeccionismo, isto é, a idéia de que a decomposição de matérias animais e vegetais levava a formação dos miasmas ${ }^{4}$, tendo o indivíduo doente capacidade de agir negativamente sobre o são e alterar a qualidade do ambiente circundante.

${ }^{2}$ Utilizamos como referência de análise os registros de óbitos da Freguesia de Nossa Senhora da Vitória, as leis e regulamentos da província do Maranhão, bem como os periódicos: Publicador Maranhense, O Estandarte e jornal o Globo.

${ }^{3}$ César Augusto Marques, concluiu os seus estudos em Medicina pela Faculdade da Bahia, em 1854, e exerceu diversos cargos em São Luís. Foi medico do Corpo de Saúde do Exército, tendo servido não só no Maranhão mas também no Pará e Amazonas. Foi também Médico da Província, Comissário Vacinador, Consultor da Santa Casa, Cirurgião da Guarda Nacional, secretario da Comissão de Higiene Pública entre outros cargos exercidos. A coroa portuguesa deu-lhe o título de cavaleiro da Ordem de Cristo, além de ter sido cavaleiro da Ordem da Rosa e correspondente do Instituto Histórico do Brasil. Sua obra célebre é o Dicionário histórico-geográfico da Provincia do Maranhão, publicado em 1870 e que traz bastante informações sobre os surtos epidêmicos na capital e a construção de locais de sepultamento em São Luís.

${ }^{4}$ Exalações perniciosas advindas principalmente da decomposição de material de origem animal expostos inadequadamente nas cidades. 
No Brasil, ao que parece, tivemos a primazia das teorias infeccionistas o que influenciou diretamente na implantação de várias reformas urbanas, principalmente a partir da segunda metade do século XIX. As áreas pantanosas e outras regiões baixas seriam o principal local de criação dos "vapores miasmáticos" e o fator diferencial do clima brasileiro para com outras realidades da Europa era a alta umidade, que proporcionava a formação de um clima quase sempre perigoso. Ou seja, um estado constante de contaminação do ar que levaria ao desenvolvimento mais freqüente de vapores pestilentos resultantes da decomposição orgânica.

Como havia a crença de que o principal meio de contágio era o ar contaminado por infecções miasmáticas, os enterramentos realizados nas igrejas logo receberam as primeiras interdições. As exalações advindas dos cadáveres enterrados nos templos religiosos passaram a ser vistas como perniciosas à saúde, causando doenças e facilitando a propagação das epidemias. Era preciso construir novos locais de sepultamento, para que o contato entre vivos e mortos fosse o mínimo possível, purificando assim o ar citadino. O lugar idealizado para os novos locais de sepultamento era fora do ambiente urbano, evitando-se a contaminação do ar. Com os surtos epidêmicos, maximizava-se a idéia de acabar com os sepultamentos nas igrejas e transferi-los para fora do espaço dos templos religiosos.

João José Reis (1991, Pág. 248), discute a idéia de que uma das principais provas do afastamento entre vivos e mortos ao longo do século XIX era a difusão do projeto de transferir os enterros das igrejas para cemitérios longe do espaço urbano, separando, assim, a sociedade dos vivos da sociedade dos mortos. A partir do desenvolvimento de argumentos higiênicos, no século XIX, os médicos brasileiros adquiriram grande importância, tornando-se uma espécie de "heróis civilizadores" 5 . A classe médica brasileira pretendia ver implantadas no país as medidas européias para o problema dos enterros nas igrejas e a solução seria a transferência dos enterramentos para locais longe das fontes d'água e onde os ventos soprassem contrariamente ao ambiente urbano, evitando-se assim surtos epidêmicos.

\footnotetext{
${ }^{5}$ Quase sempre nos pareceres contra os enterros nas igrejas em São Luís eram chamados médicos de renome na cidade para, através de pesquisas, tornar públicas suas posições contrárias aos enterramentos nos templos religiosos. Os mais requisitados para expor suas opiniões acerca do tema eram: Augusto César Marques, José da Silva Maia, José Maria Faria de Matos, Antonio Henriques Leal e José Sérgio Ferreira.
} 
Em 1828, com a promulgação da "Lei Imperial de Estruturação dos Municípios", as câmaras municipais assumem a responsabilidade de proporcionar às cidades brasileiras uma melhor disposição do lixo nas vias públicas, um melhoramento do escoamento das águas usadas, do alinhamento desordenado das ruas, da arquitetura inadequada dos prédios, e principalmente a reorganização e racionalização de algumas instituições, como os hospitais, prisões, escolas e cemitérios, todos vistos então como causadores de malefícios físicos e morais aos vivos. Nesse sentido, a lei de $1^{\circ}$ de outubro de 1828, proposta pelo Império, teve como objetivo estabelecer padrões para a gestão municipal e suas competências.

Entretanto, a campanha contra os odores somente viria a fazer sentido em épocas de epidemias, período em que o índice de mortalidade elevava-se em um curto espaço de tempo. Com a epidemia de varíola de 1855 em São Luís, as resoluções contra as sepulturas eclesiásticas aumentaram, pois com o caráter ainda mais avassalador desse surto, as autoridades locais buscaram acabar definitivamente com os sepultamentos nas igrejas e construir novos cemitérios longe das cidades, seguindo as normas higiênicas da época, a fim de evitar a contaminação dos vivos pela decomposição dos mortos.

Em 1855, momento de acirramento do surto epidêmico de varíola, segundo as estatísticas dos mortos publicadas nos jornais ${ }^{6}$, percebe-se que a maioria da população enterrada no Cemitério da Misericórdia de São Luís havia sido acometida pela "peste”. Em curto espaço de dez dias, 51 pessoas haviam sido vítimas da varíola. Isso somente no início de janeiro. O número era igual a quase todos os óbitos do mês de dezembro de 1854. Para as autoridades locais, o mal havia "encrudelecido" visivelmente, o que deixava a população ainda mais alarmada e assustada com tais notícias. Foram estas as estatísticas dos mortos publicadas no jornal "Publicador Maranhense", nos primeiros dias do mês de janeiro de 1855:

- Os cadaveres enterrados no cemiterio da Misericordia aos 6 dias que decorreram de 5 a 10 do corente, moutam a 40. Os mortos da Bexiga são 29; Ao todo 51 pessoas victimas da peste no curto espaço de dez dias; quase tantas como durante todo o mez de dezembro. O mal encruece visivelmente. (JORNAL PUBLICADOR MARANHENSE - Quinta-feira, 11 de Janeiro de 1855. P.3)

\footnotetext{
6 Encontramos tais informações principalmente nos jornais "PUBLICADOR MARANHENSE" e
} "CHRONICA MARANHENSE". 
Em 1850, é publicado em São Luís um tipo de manual de como prevenir surtos epidêmicos: "Medidas Sanitarias Adoptadas na Provincia do Maranhão para evitar a epidemia da febre amarella, com o regulamento de saude dos portos”, escrito pelo médico José da Silva Maia, que adquiriu grande notoriedade no que diz respeito à propagação do higienismo no Maranhão. O objetivo de tal obra era impedir que a epidemia de febre amarela, que atingia outras províncias, principalmente a Bahia, chegasse ao Maranhão pelas embarcações que aqui ancoravam para descarregar mercadorias, inclusive escravos.

Nesta obra, um artifício bastante utilizado para conter os surtos em São Luís eram as quarentenas ${ }^{7}$. Estas serviam para que as autoridades analisassem a existência de algum vestígio de morte no navio em virtude de alguma doença contagiosa. A realização de inspeções higiênicas parece ter se tornado uma prática recorrente em São Luís quando do aparecimento das primeiras epidemias.

(...) em que se declare o nome das embarcações que entrarão e forão sujeitas á visita da saúde, d'onde vem, e os dias que trazem de viagem, á quem vem consignadas, e o que colheu de seus papeis e das perguntas feitas ás pessoas de bordo, o numero dos indivíduos da tripulação, e dos passageiros, com os nomes destes, e do capitão ou mestre, e o estado de saúde de toda a gente a bordo. E se as embarcações forem declaradas em Quarentena, dirá qual o motivo, dando neste caso uma nota minuciosa de seus carregamentos, e indicará cada dia a natureza das operações que praticar tanto á bordo para a ventilação -, desinfecção, e purificação das tripulações, mercadorias e porões... determinar-lhe o tempo que deve reter as embarcações, fazendas e indivíduos em quarentena. (MEDIDAS SANITARIAS ADOPTADAS NA PROVINCIA DO MARANHÃO PARA EVITAR A EPIDEMIA DA FEBRE AMARELLA, COM O REGULAMENTO DE SAUDE DOS PORTOS, 1850, P. 5).

Para evitar a importação ou o progresso de surtos epidêmicos, segundo alguns adeptos do contagionismo, era conveniente o estabelecimento das quarentenas para analisar possíveis focos de contágio nas embarcações ancoradas na Ilha. Encontrado algum vestígio de epidemias, era feita a remoção dos pestosos para lugar retirado, de onde o foco do contágio não pudesse prejudicar os habitantes da cidade. Já para os infeccionistas, tais medidas eram ineficazes, haja vista que defendiam medidas mais eficazes para transformar o

\footnotetext{
${ }^{7} \mathrm{O}$ cuidado com as embarcações que aqui ancoravam se intensificou durante o século XIX, notadamente os navios que traziam escravos, devido à crença de que a maioria dos surtos viria com os cativos capturados na África. Segundo diversas autoridades médicas, haveria relação entre a ocorrência de secas e fome em algumas regiões do continente africano e o aparecimento de surtos de varíola, e que eram trazidos quando da transladação desses escravos para o Brasil.
} 
ambiente urbano de São Luís um local mais higiênico, impedindo a formação dos temidos "vapores miasmáticos".

A fiscalização contra novas epidemias intensificou-se principalmente quando da notícia e confirmação de que as mortes que assolavam principalmente a Bahia, mas também Pernambuco e Pará, eram provenientes da tão temida febre amarela. Era preciso evitar, por intermédio de medidas fiscalizadoras duras, a chegada de algum navio contaminado a estes portos, pois talvez a cidade, que já padecia com seus surtos de varíola, não fosse capaz de resistir ao caráter também mortífero da febre amarela.

As causas da epidemia de febre amarela na Bahia deviam servir de exemplo para São Luís, para que esta não sofresse desse mal avassalador. Era preciso ainda, segundo o "manual preventivo da febre amarela" de César Maia,

Evitar igualmente as grandes reuniões de povo, ainda que seja dentro das igrejas, as occasiões de cólera e accessos de raiva e quaesquer outras affecções moraes tristes, as vigilias prolongadas, as fadigas e todos os excessos em quaesquer actos da vida que tendão a enfraquecer o corpo e a diminuir a resistencia da econommia aos agentes externos. (MEDIDAS SANITARIAS ADOPTADAS NA PROVINCIA DO MARANHÃO PARA EVITAR A EPIDEMIA DA FEBRE AMARELLA, COM O REGULAMENTO DE SAUDE DOS PORTOS, 1850, P. 21).

As igrejas eram quase sempre citadas, pois estavam entre os locais que, principalmente em períodos de festividades, recebiam o maior número de pessoas. Isso porque, quando do período de enterramento nas igrejas, era preciso que os parentes, amigos, irmãos de confraria ali sepultados, recebessem as orações realizadas para o descanso eterno de suas almas.

Soma-se a isso a crença de que o estado de humor das pessoas influenciava decisivamente na propagação das epidemias. Era preciso que, mesmo nos momentos de surtos epidêmicos em que os ânimos se exaltavam - com a perda de parentes, amigos, cativos - houvesse o cultivo da alegria nos corações dos indivíduos. Tristeza e melancolia eram sinônimos de doença e morte.

Algumas mudanças nas práticas cemiteriais são percebidas principalmente nos momentos mais intensos das epidemias. O costume de conduzir o morto, por exemplo, em caixões abertos para que todos os que acompanhavam o cortejo pudessem ter um contato mais próximo com o falecido vai aos poucos sendo alvo de interdições. A recomendação era que os caixões fossem conduzidos de forma que ficassem hermeticamente vedados, evitando assim a propagação dos vapores cadavéricos considerados prejudiciais à saúde dos vivos e condutores de epidemias. Além disso, os vários dobres de sinos e as 
encomendações dos defuntos precisavam primar agora pelo silêncio, para que assim não deixasse a população assustada com o caráter arrasador dos surtos epidêmicos. Vejamos a seguinte citação:

Ainda não houve uma auctoridade que mandasse cessar na quadra actual os dobres dos sinos; nem os acompanhamentos e encomendações dos defuntos em altas vozes, nem desviar de sobre os enfermos o expetaculo da extrema-unção, morte e mortalha! (JORNAL O ESTANDARTE. QUINTA FEIRA 1 DE FEVEREIRO DE 1855, Nº 8, PÁG. 3).

O motivo principal para tais tentativas de mudanças parece ter sido a crença de que as emoções em demasia influenciavam na obtenção de doenças, haja vista que era preciso evitar raivas, medos exacerbados, pois tudo isso gerava uma fraqueza maior ao organismo, tornando as pessoas mais suscetíveis às epidemias.

\begin{abstract}
A epidemia de 1855 trouxe também mudanças nos espaços utilizados para o sepultamento dos indivíduos em São Luís. Devido às precárias condições do cemitério da Misericórdia neste ano, momento de acirramento da epidemia de varíola, as autoridades locais resolveram por fim, mesmo que provisoriamente, aos sepultamentos neste recinto, transferindo-os para o cemitério da Irmandade Bom Jesus dos Passos. Digo temporariamente porque cabia à irmandade da Misericórdia a construção de um novo cemitério capaz de abarcar a quantidade de mortos na capital.
\end{abstract}

- Salubridade Publica. - Por ordem superior sobrestarão-se os enterramentos no cemiterio da Santa Casa da Misericordia, por já estar o seu terreno completamente saturado de materias animaes, e por isso sem as condições indispensaveis para à prompta decomposição dos cadaveres; de ha muito que o bem publico reclamava com urgencia esta medida. Está substituindo-o provisoriamente o cemiterio da confraria dos passos, até que a da mizericordia mande edificar outro com as proporções convenientes, para o que dizem que já escolheu o terreno no lugar denominado, Gavião, ao sul da cidade e fóra dos limites della. Consta-nos que o sr. Dr. Antonio Henriques Leal, ilustre medico desta cidade, nomeado perito para dar o seu parecer a este respeito pelo sr. Dr. Chefe de policia... (JORNAL PUBLICADOR MARANHENSE. SEXTA-FEIRA 13 DE ABRIL DE 1855. N. 1658. P.3.).

O cemitério da irmandade Bom Jesus dos Passos, todavia, também possuía seus problemas, pois, segundo relatos médicos, encontrava-se próximo à cidade não proporcionando a dissipação dos vapores cadavéricos, o que o tornava perigoso para a saúde da população. Além disso, o cemitério estava situado sobre "o único ponto que se offerece aos convalescentes, e mais habitantes d'esta cidade, para seus passeios hygienicos, ou desimples destração”. (Jornal O Estandarte. Quinta Feira 4 de Maio de 1854. Vol. V, Pág. 2).

Era preciso que se tomasse algumas medidas para tornar o cemitério dos Passos não prejudicial à saúde dos vivos. As principais sugestões dos higienistas locais eram: a observação da regra de não reutilizar alguma sepultura antes do prazo mínimo de três anos, lançar uma quarta de cal 
sobre todos os corpos ali sepultados, além de abater as grandes árvores que impediam a livre circulação do ar no local.

A necessidade dos passeios higiênicos tinha como intuito também demonstrar um padrão de normalidade nas práticas cotidianas dos indivíduos na cidade, mesmo nos momentos acirrados da peste. A censura às grandes aglomerações de pessoas estava ligada a necessidade de que houvesse a livre circulação do ar nos lugares de maior visitação pelos transeuntes. Para tanto, a pouca ventilação existente nos templos religiosos, teatros e que recebiam um grande fluxo de pessoas quase que diariamente, tornava-se um foco propício para o desenvolvimento de vapores pestilentos. Logo, desde que os passeios higiênicos fossem realizados em locais bastante arejados, poderiam contribuir para distrair os humores e levar um ar saudável no retorno das pessoas aos seus recintos.

Vejamos ainda a seguinte recomendação para o melhoramento do cemitério da irmandade Bom Jesus dos Passos:

Facilitar a execução d'esta medida, diminuindo o numero de cadaveres a sepultar-se. Obtem se isto passando-se pelo dissabor de se não conceder sepulturas aos pobres, tornando assim o cemitério mais privativo. (JORNAL O ESTANDARTE. QUINTA FEIRA 4 DE MAIO DE 1854. VOL. V, PÁG. 2).

O cemitério da irmandade de Bom Jesus dos Passos recebia um número de indivíduos pobres e desvalidos infinitamente inferior em comparação com o cemitério da Santa Casa da Misericórdia, ficando reservado o cemitério dos Passos para enterramento dos irmãos da irmandade, e que quase sempre eram figuras ilustres da sociedade ludovicense. Contudo, com a interdição temporária do cemitério da Misericórdia o cemitério dos Passos foi obrigado a enterrar boa parte dos menos aquinhoados na capital, o que nos faz compreender a recomendação colocada pelo jornal "O Estandarte". Se esta recomendação de evitar-se o enterro de pobres no cemitério da irmandade Bom Jesus dos Passos foi levada a sério, em que local passaram a ser enterrados boa parte dos desvalidos na capital, haja vista que o cemitério dos Passos já estaria substituindo o então superlotado cemitério da Misericórdia?

Mesmo com os cemitérios da Misericórdia e dos Passos em São Luís, aos indivíduos de categorias sociais consideradas superiores ainda era possível concessões de enterramentos nas igrejas: "O enterro do ilustre finado teve logar hontem de tarde ás 5 e meia para as 6 horas. O seu corpo jaz no cemitério de S. João Baptista”. (JORNAL PUBLICADOR MARANHENSE. Sábado 12 de Março de 1855. P.3.).

Esta "tradicional" forma de sepultamento não podia sucumbir de forma tão abrupta, pois o imaginário ${ }^{8}$ de que os enterramentos nas igrejas facilitavam na aceitação dos indivíduos em um possível plano celeste ainda fazia parte do cotidiano das pessoas. Ainda que em quantidade consideravelmente menor, as referências a enterramentos nos templos

\footnotetext{
${ }^{8}$ Trabalho o conceito de imaginário a partir da perspectiva de Sandra Pesavento em que: "O real é sempre o referente da construção imaginária do mundo, mas não é o seu reflexo ou cópia. O imaginário é composto de um fio terra, que remete às coisas, prosaicas ou não, do cotidiano da vida dos homens, mas comporta também utopias e elaborações mentais que figuram ou pensam sobre coisas que, concretamente não existem. Há um lado do imaginário que se reporta à vida, mas outro que se remete ao sonho, e ambos os lados são construtores do que chamamos de real. PESAVENTO, Sandra Jatahy. História e História Cultural - Belo Horizonte: Autêntica, 2003, Pág. 47.
} 
religiosos continuaram mesmo depois da epidemia de varíola que acometeu São Luís em 1855 .

Entretanto, nos lugares onde houvesse cemitérios já construídos era proibida a continuidade dos enterramentos nas igrejas, conforme veremos a seguir:

Dos cemiterios e enterramentos de cadaveres

Art. 87. Nos lugares onde houverem cemiterios legalmente instituidos, fica prohibido o enteramento de cadaveres nas igrejas

Aos contraventores, inclusive os parochos, fabriqueiros e procuradores de irmandades multa de dez mil reis. (LEIS E REGULAMENTOS DO MARANHÃO. 27 DE DEZEMBRO DE 1856).

O fato de em 1856 ainda encontrarmos referências a proibições de enterramentos nas igrejas nos remete a problematizar a prática ainda de sepultar os mortos nos templos religiosos, mesmo com a existência de cemitérios longe do espaço dos templos em São Luís. Além disso, a referência às multas que recairiam também para os párocos, fabriqueiros e procuradores das irmandades, dá-nos indícios de que seriam estes os principais responsáveis por resguardar ainda a "mentalidade cristã" pela qual perpassavam os sepultamentos nas igrejas, burlando assim as principais teorias higiênicas. A referência às multas talvez fosse o último recurso a ser utilizado para coibir a resistência da Igreja em pôr fim aos enterramentos nos templos religiosos.

O presidente da provincia, attendendo que não é possivel continuar a inhumação de cadaveres no cemiterio da santa casa de misericordia desta cidade, em que dahi provenhão consideraveis damnos á salubridade publica, visto que, segundo os exames, á que se procedeo, não póde a área do referido cemiterio receber mais cadaveres, não estando, por outro lado, em proporção com a mortalidade da capital, pois contem apenas um terço das sepulturas necessárias. (LEIS E REGULAMENTOS DO MARANHÃO. 3 DE ABRIL DE 1855, Pág. 173)

Em 1855 o terreno do cemitério da Misericórdia já se encontrava praticamente esgotado, sendo a epidemia apenas o estopim da crise de falta de sepulturas. Soma-se a isso o fato de que a quantidade de mortos neste ano foi tamanha que deixou as autoridades locais sem outra alternativa a não ser interditar o cemitério da Misericórdia e transferir os sepultamentos para outro local, no caso o cemitério da irmandade Bom Jesus dos Passos. Contudo, havia um prazo para tal interdição, pois "Fica prohibida a inhumação de cadaveres no cemiterio da Santa Casa da Misericordia desta cidade durante o espaço de cinco annos" (LEIS E REGULAMENTOS DO MARANHÃO. 27 de Dezembro de 1856, Pág. 173). 
Com a remissão da "peste", a Misericórdia poderia retomar a primazia dos principais serviços fúnebres, mas, ao que parece, além da diminuição dos efeitos da varíola, buscava-se dar chance à Misericórdia de construir um novo cemitério para que assim a instituição continuasse monopolizando os enterramentos na capital. Nesse espaço de cinco anos cabia ao cemitério da irmandade Bom Jesus dos Passos a realização dos sepultamentos em São Luís.

Art.2. Em quanto se não procede à construção de um cemiterio provisorio terá lugar a inhumação no cemiterio á cargo da irmandade do senhor bom jesus dos passos, cuja permissão será previamente solicitada. (LEIS E REGULAMENTOS DO MARANHÃO. 27 DE DEZEMBRO DE 1856, PÁG. 173).

Nesse ínterim, uma Junta de Higiene seria formada na capital a fim de escolher o local mais apropriado para a construção de um novo cemitério que pudesse abarcar a quantidade de mortos existentes na capital.

Art.3. Junta de Hygiene publica desta cidade, entendendo-se com o Dr. chefe de policia da
provincia, passará quanto antes a tomar as medidas hygienicas necessarias para o
desinfectamento do cemiterio da santa casa, e, com o engenheiro dr. Raimundo Teixeira Mendes
e visconde de Saint- Armand, a indicar o logar mais conveniente para o estabelecimento de um
novo cemiterio. (LEIS E REGULAMENTOS DO MARANHÃO. 3 DE ABRIL DE 1855. PÁG.
173). Caberia a "Junta de Higiene Publica" providenciar a desinfecção do cemitério da Santa Casa, além da indicação de um novo local de sepultamento, seguindo os novos padrões: um local de enterramento longe da cidade, das fontes d'água, basicamente distante da fonte do Apicum, principal meio de abastecimento de água da capital na época, onde os ventos soprassem contrariamente ao ambiente citadino. Além dos médicos que vão adquirindo notoriedade ao decorrer do século XIX, os engenheiros também estariam encarregados de dar uma nova ordenação à cidade, indicando os lugares mais adequados para a construção de escolas, hospitais, prisões, e também dos novos cemitérios.

Em 1855, portanto, é comprado um terreno para a edificação do novo cemitério da Misericórdia. O novo cemitério de São José da Misericórdia ficava na Rua do Passeio, na Quinta do Gavião, principiando a funcionar no dia 6 de Setembro de 1855, adotando depois o nome de Cemitério do Gavião devido a sua localização. Para que os vivos pudessem ter um local onde orar por seus mortos, este ganhou no mesmo dia uma capela, sob a proteção de São José. 
No que diz respeito à continuidade dos enterramentos nas igrejas, com a construção do novo cemitério da Misericórdia, ou Cemitério do Gavião em 1855, as referências aos sepultamentos em templos religiosos ficam ainda mais esparsas em São Luís. A partir de 1856, a legislação proibindo os enterros nas igrejas parece ter sido mais severamente seguida, visto que o então presidente da província José Olimpo Machado, que aprovou diversas resoluções em favor dos novos cemitérios, precisou que a câmara municipal baixasse uma lei permitindo o seu sepultamento em uma igreja da capital: "Fica definitivamente approvado a resolução da Camara Municipal desta cidade, determinando que se désse sepultura na Cathedral ao cadáver do presidente doutor Olimpo Machado”. (LEIS E REGULAMENTOS DO MARANHÃO. 14 de Agosto de 1856, P. 35).

\section{REFERÊNCIAS}

\section{BIBLIOGRAFIA}

CHALHOUB, Sidney. Cidade Febril: cortiços e epidemias na corte imperial - São Paulo: Companhia das Letras, 1996.

COSTA, Jurandir Freire. Ordem médica e norma familiar. 3. ed. Rio de Janeiro: Graal, 1989.

CRESPO, Jorge. A História do Corpo. Lisboa, Difel, 1990.

MARQUES, César Augusto. Dicionário Histórico e Geográfico da Província do Maranhão. Rio de Janeiro, Fon-Fon - Seleta, 1970.

PESAVENTO, Sandra Jatahy. História e História Cultural - Belo Horizonte: Autêntica, 2003.

REIS, João José. A Morte é uma Festa: ritos fúnebres e revolta popular no Brasil do século XIX. São Paulo: Companhia das Letras, 1991.

VIGARELLO, Georges. O limpo e o sujo: uma história da higiene corporal. São Paulo: Martins Fontes, 1996.

DOCUMENTAÇÃO PRIMÁRIA

JORNAL PUBLICADOR MARANHENSE. Quinta-feira, 11 de Janeiro de 1855. P.3. 
JORNAL PUBLICADOR MARANHENSE. Sábado, 12 de Março de 1855. P.3.

JORNAL PUBLICADOR MARANHENSE. Sexta-Feira, 13 de Abril de 1855. P.3.

JORNAL O ESTANDARTE. Quinta Feira, 1 de Fevereiro de 1855, P. 3.

JORNAL O ESTANDARTE. Quinta Feira 4 de Maio de 1854, Pág. 2.

LEIS E REGULAMENTOS DO MARANHÃO. 23 de Dezembro de 1853. Pág. 6. Colleção de Leis, Decretos e Resoluções da Província do Maranhão. ORMA 328 M311 (1849-54).

LEIS E REGULAMENTOS DO MARANHÃO. 3 de Abril de 1855, Pág. 173. Colleção de Leis, Decretos e Resoluções da Província do Maranhão. ORMA 328 M311 (1854-58).

LEIS E REGULAMENTOS DO MARANHÃO. 14 de Agosto de 1856. Pág. 35. Colleção de Leis, Decretos e Resoluções da Província do Maranhão. ORMA 328 M311 (1854-58).

LEIS E REGULAMENTOS DO MARANHÃO. 27 de Dezembro de 1856, Pág. 121. Colleção de Leis, Decretos e Resoluções da Província do Maranhão. ORMA 328 M311 (1854-58).

MARANHÃo. Medidas Sanitarias Adoptadas na Provincia do Maranhão para Evitar a Epidemia da Febre Amarella, com o Regulamento de Saude dos Portos. Typ. Constitucional de I. J. Ferreira, 1850. 